\title{
Changes of Water Quality in Hamilton Canal in Sri Lanka
}

\section{Chandrasekara C.M.K.N.K. ${ }^{{ }^{*}}$, Weerasinghe K.D.N. ${ }^{2}$, Piyadasa R.U.K. ${ }^{1}$ and Pathirana $\mathrm{S}^{3}$}

\author{
${ }^{1}$ Department of Geography, University of Colombo, Colombo-03, Sri Lanka. \\ ${ }^{2}$ Department of Agricultural Engineering, Faculty of Agriculture, University of Ruhuna, \\ Kamburupitiya, Sri Lanka \\ ${ }^{3}$ School of Environmental Science and Management, Southern Cross University, Australia. \\ "kanchanachandrasekara@gmail.com
}

\begin{abstract}
The Hamilton canal is a manmade watercourse that was constructed along the western boundary of the Muthurajawela wetlands. The canal has two segments that connect Kelani estuary and Maha oya estuary to Negombo lagoon. The present study has been carried out to identify the spatial and temporal water quality changes in the Hamilton canal. Sampling was carried out in 8 locations using 40 samples with respect to surface, middle and bottom layers of each sampling point and at the two banks of the same sampling point. In situ testing of Electrical Conductivity (EC), salinity, $\mathrm{pH}$, turbidity and temperature were carried out in monthly intervals during October 2012 to March 2013. Laboratory tests were performed to detect heavy metals, zinc, copper and chromium for five selected water samples.

EC values of water in all three layers of the entire canal varied between 337 and 48,320 $\mu \mathrm{s} / \mathrm{cm}$. Spatial variation of the salinity of the water varied between 0.2 and $29.6 \mathrm{ppt}$. The variation of EC and salinity increased vertically from top to bottom owing to the density of water. $\mathrm{pH}$ varied from 6.6 to 7.9 maintaining an environmentally sound level. Turbidity of the water ranged from 1 to $78 \mathrm{NTU}$ while temperature fluctuated between $27-34^{\circ} \mathrm{C}$ during the considered period. Concentration of Heavy metals was very low during the study period. Zinc concentrations ranged between 0.25-0.54 ppb and chromium between 0.28-0.54 ppb. Copper concentrations ranged between $0.22-0.65 \mathrm{ppm}$ and concentration of all the cations were below the threshold level for human consumption.

Results revealed that the EC and Salinity levels demonstrate a negative relationship with precipitation while EC, salinity and turbidity levels demonstrate a positive relationship with depth of the water column. There were no significant changes in $\mathrm{pH}$ of the canal water. It can be concluded that the salt dynamics of the canal is significantly different in its two segments which is due to the influence of the lagoon and interconnected estuaries.
\end{abstract}

Keywords: Salinity, Heavy metals, Water quality 